\title{
O padrão linear de apresentação das informações: uma opção possível
}

\author{
Flávia Ataide Pithan; Doutoranda do PPGCOM - PUCRS; fpithan@univates.br \\ Maria Isabel Timm; Doutora pelo PPGIE - UFRGS; beta@cesup.ufrgs.br \\ Raymundo Carlos Ferreira Filho; Doutorando do PPGIE - UFRGS; paka@ufrgs.br \\ Gabriela Trindade Perry; Doutoranda do PPGIE UFRGS, gabrielaperry@hotmail.com
}

The linear standard presentation of the information: a possible option

Este trabalho discute a importância de utilizar recursos educacionais de navegação mais linear do que os hipertextos, atendendo as necessidades de acesso a conteúdo extenso, de áreas científicas e tecnológicas. Relata o desenvolvimento de livros de Engenharia Civil para a Internet, especificamente para a área da Engenharia Geotécnica, destacando-se diferenças de processos de produção, visando facilitar a concentração dos alunos e a organização da navegação.

Palavras-chave: linearidade, hipertextualidade, design de interface, informática na educação, Engenharia Geotécnica.

This work argues the importance to use educational resources of the navigation more linear than the hypertexts, taking care of the access necessities to the extensive content of scientific and technological areas. It tells the book development of Civil Engineering for the Internet, specifically for the area of Geotechnical Engineering, highlighting differences of production processes, aiming to facilitate the students concentration and the navigation organization.

Key Words: linearity, hypertextuality, design of interface, computer science in the education, Geotechcnical Engineering.

Em 1989 surge a World Wide Web, um novo serviço da Internet. Após esta criação, a Internet começa a se tornar popular, sendo que o marco desta transformação foi o lançamento da primeira versão do navegador Mosaic, desenvolvido por Marc Andreessen e Eric Bina no National Center for Supercomputing Applications (NCSA) da Universidade de Illinois. Este software possibilitava navegar pela Internet através de uma interface gráfica. Neste momento, surge o embrião do acesso a conteúdo multimídia pela World Wide Web (WWW ou Web), ampliando a criação de Berners-Lee (2005) que implementava algumas idéias de Bush (2005) e Nelson (2005), e que possibilitaria o tráfego de conteúdo como imagens, textos, sons e vídeos através de uma rede com dispositivos heterogêneos usando HTML (Ferreira Filho, 2005). 
Em meados da década de 90 do Século XX, começam a ser disseminadas as discussões sobre as formas não-lineares da produção de informação e conhecimento, abrindo espaço para a navegação através das interfaces cada vez mais ricas em multimídia ${ }^{1}$. Os hipertextos entraram na moda, em verso, prosa, matérias jornalísticas, livros e papers acadêmicos, que discutiram exaustivamente as vantagens da associação de idéias, como uma forma ergonômica ao pensamento humano e desejável ao ritmo da exploração do usuário (Levy, 1993, Timm, 2006). Do ponto de vista educacional, consolidou-se a importância da disponibilização - e do estímulo - à interatividade, em níveis variados e, se possível, em sua forma mais completa, que seria a construção total de sentidos pelo próprio aluno, a partir de sua própria necessidade e interesse de navegação. Mais de uma década após o fantástico boom hipertextual, a produção de tecnologias educacionais amadureceu o suficiente para permitir às equipes produtoras 0 necessário distanciamento crítico para saber que a interatividade é boa, mas não é a única solução e, talvez, nem seja sempre a melhor delas, dependendo das necessidades do momento do estudo, do nível dos alunos e das exigências do próprio conteúdo, desde que todas estas variáveis sejam vistas como parte de uma visão sistêmica de planejamento de atividades, virtuais, como por exemplo os cursos à distância (Moore e Kearskey, 1996).

Um bom planejamento do material a ser produzido deve obrigatoriamente iniciar pela compreensão das necessidades e do nível educacional do público-alvo, bem como da complexidade do conteúdo e suas exigências de concentração e disciplinamento mental que serão necessárias para a compreensão desse conteúdo. É o caso das áreas científicas e tecnológicas, as quais, por sua própria natureza, exigem objetividade, pragmatismo e síntese de conteúdos extensos, estruturação objetiva de idéias e conteúdos cumulativos, os quais, muitas vezes, precisam ser apresentados de forma linear e estruturada. $\mathrm{O}$ acesso a esse tipo de informação e conhecimento redimensiona, por exemplo, uma expressão muitas vezes associada à navegação hipertextual, que é o aprendizado lúdico, uma vez que o próprio conteúdo, para os estudantes e estudiosos destas áreas, constitui-se no aspecto prazeroso do aprendizado, tornando completamente desnecessária a busca de sofisticadas estratégias de navegação hipertextual, ou mesmo de animações bem vistas pelo público infantil ou juvenil ${ }^{2}$.

Verdade que ainda não há metodologia de pesquisa suficientemente robusta para medir a eficiência do material produzido, com variáveis claras que possam ser medidas e comparadas, em relação aos tipos e formas de aprendizado. Enquanto não são consolidadas estas metodologias de pesquisa, prosseguem as atividades de produção de materiais educacionais, explorando diversas possibilidades de acesso e navegação, como, por exemplo, os livros virtuais, que viabilizam a organização e apresentação de grandes quantidades de conteúdo estruturado. É possível que existam elementos a serem desenvolvidos na apresentação desta hipertextualidade restrita, que possam, por si, apoiar ou prejudicar a apreensão dos conteúdos, tema que igualmente aponta para a necessidade de desenvolvimento de metodologia de pesquisa e estratégias de experimentação de formas, que possam levar a novos e importantes conhecimentos para a produção de tecnologia educacional. 


\section{Livros na internet}

Sempre que surge uma nova tecnologia, os pesquisadores temem pelo desaparecimento das formas anteriores de produção de conhecimento. Foi assim desde a antiguidade clássica, quando os gregos temiam que a escrita, recém descoberta, fosse acabar com a nobreza da memória humana, considerada um atributo divino ${ }^{3}$, que dava suporte à transmissão de conhecimentos, através de poemas, relatos míticos e outras técnicas de apoio mnemônico (Lévy, 1993). Dizia-se que a fotografia iria terminar com a pintura, que o rádio eliminaria as apresentações musicais, que a televisão eliminaria o rádio ou o cinema e, por fim, que a internet eliminaria o livro (Munari, 1997). Verdade que ainda é cedo para decretar que a última afirmação, como as demais, não se confirmará, mas há argumentos que não podem ser esquecidos. Um deles, já aventado por Nicholas Negroponte, nos primórdios da vida digital, título de um dos primeiros livros do autor, a descrever o novo mundo mesclado por bits e átomos ${ }^{4}$ (Negroponte, 1999): os amantes do livro em papel, portável em situações tão diversas quanto a escrivaninha ou a cama, esquecem que a tela de computador como a conhecemos hoje não será o suporte das futuras produções. Telas maleáveis, manipuláveis com um toque semelhante ao papel ou tecido, dobráveis e completamente portáveis era o que o visionário autor já prenunciava, há quase uma década.

Hoje, os livros eletrônicos já saíram da tela do computador e são disponibilizados em tamanho equivalente ao de livros de bolso. Mas essa evolução não pára por aí, já existe o papel eletrônico. O primeiro surgiu em 2000, desenvolvido pela unidade de pesquisa e desenvolvimento da Lucent Technologies (Niederauer, 2007).

Nesse sentido, o que parece claro é que não deverá ser substituída pela Internet a natureza do livro, como um conjunto estruturado de informações objetivamente organizadas, de forma razoavelmente linear, com acessos facilitados a várias de suas partes - aí sim - pela navegação hipertextual, devidamente robusta para favorecer a localização do leitor; e com ilustrações - aí sim, novamente - que apóiam a visualização de detalhes, movimentos, etc. Não só provavelmente não será substituída, como uma ou várias formas de livro virtual deverão ser parte integrante do universo de recursos disponíveis através da Internet, tanto quanto a memória humana integrou e alimentou a escrita; a fotografia dialogou com a pintura e o cinema alimentou-se do rádio e a televisão, criando sua própria linguagem áudio-visual que, por sua vez, re-alimentou a forma e o conteúdo dos seus meios de origem. No caso do uso educacional dos livros em novos suportes, mediados através da Internet (ou do celular, ou dos futuros equipamentos convergentes, ou de receptores flexíveis imitando papel...), cabe aos produtores dominar suas linguagens e seus desafios, de forma a atender às necessidades de cada conteúdo, cada público e cada etapa do processo educacional, usando de criatividade sem perder a noção de bom senso para entender as reais necessidades de público e de conteúdo. A hipertextualidade deve estar a serviço de ambos, e não o oposto. 
A integração de livros em ambientes educacionais, bem como a exploração de seu uso, em projetos didático-pedagógicos complexos e flexíveis, para atender a área de Engenharia, foi objeto do trabalho apresentado a seguir. A experiência de desenvolvimento desses materiais didático-digitais, ou seja, livros e apostilas digitais, foi realizada ao longo de três editais de pesquisa concebidos pela SEAD - UFRGS ao departamento de Engenharia Civil. A área específica em questão é a Engenharia Geotécnica e os livros foram inseridos num ambiente de ensino digital denominado ENGEO 5 .

\section{Padrões lineares e não lineares de apresentação das informações}

A apresentação de informações de forma não linear está associada ao conceito de hipertexto, em oposição ao conceito de texto tradicional, que é unidirecional e linear; o leitor tem apenas um caminho para avançar na informação. De acordo com Oliveira e Fernandes (2004),

Os textos tradicionais, impressos em papel ou em arquivos de computador, são essencialmente seqüenciais, o que significa dizer que existe apenas uma seqüência linear que determina a ordem em que o texto pode ser lido. Para acessar as informações, avança-se ou retrocede-se nas páginas do texto ou do arquivo (p. 2).

No hipertexto as informações são acessadas de forma não linear, através de nós que estabelecem os links para os saltos entre as partes da informação. O termo hipertexto "se refere a um hiperdocumento ativo em um sistema hipermídia" (ibid., p. 3). No caso deste trabalho, pode-se exemplificar este conceito através do conjunto de páginas visualizado em algum navegador dos livros digitais em questão. Documentos mais próximos de uma forma estrutural baseada um uma hierarquia, ou seja, de uma forma mais linear, permitem ao usuário uma visão mais clara sobre a organização das informações. Por outro lado, documentos baseados na forma de rede, com vários links entre os nós de conteúdo, podem contribuir para distribuir a atenção do usuário, durante sua navegação em busca do conhecimento, o que, como se afirmou na introdução desse texto, pode contrariar o objetivo proposto pelo professor ${ }^{6}$. Por isso, nestes casos, é preciso ter cuidado redobrado com o projeto navegacional, tentando sempre fornecer ao usuário sua localização exata dentro da navegação e, quando necessário, priorizar a linearidade do acesso.

Pinheiro e Mendes (2007) citam que, se por um lado os materiais didáticos digitais colocam nas mãos dos alunos a gestão de sua aprendizagem, pois são eles que decidem quando passar para uma nova etapa, quando retornar a uma informação e quantas vezes estudar os pontos relevantes até que o assunto se torne familiar, por outro lado a navegação pode gerar alguns problemas como: aceder e sintetizar a informação e expor o aluno a sobrecarga cognitiva, não tendo estratégias específicas para tratar esse tipo de informação. É preciso sempre se ter presente os pontos positivos e negativos da potencialidade de materiais didáticos oferecidos via internet. 
A Engenharia Civil é uma das áreas científicas mais antigas e tradicionais. Assim, entre alternativas discutidas com os envolvidos nos projetos dos livros digitais, embora o acesso às informações seja hipertextual, optou-se pela apresentação das informações de forma também tradicional, ou seja, linear. Desta forma, ao estudante é sugerida uma seqüência otimizada de aprendizagem, onde os conteúdos vão sendo aprofundados hierarquicamente, mesmo que ao aluno seja permitido pular os capítulos dos conteúdos que já domina, utilizando-se da navegação não-linear e não-seqüencial.

No intuito de fornecer ao estudante sua localização durante a navegação nos livros digitais, o menu de acesso às informações foi disponibilizado sempre na esquerda, mantendose sempre este agrupamento. De acordo com Cybis (1997) o software ergonômico aconselha, orienta, informa e conduz o usuário na interação com o computador. Essas características permearam o desenvolvimento dos projetos, resultando em uma tela de fácil compreensão, caso se considere a ordenação, o posicionamento e a distinção dos objetos (textos, imagens e textos de navegação) apresentados. Optou-se por disponibilizar os links de forma textual, visto que este padrão de informação atinge diretamente os alunos de engenharia, além aumentar a familiaridade com o vocabulário da área, pois cada item do menu é indicado por um texto que corresponde a um termo técnico da Engenharia ao qual o capítulo se refere, conferindo flexibilidade à interface a qual se adapta a diferentes tipos e níveis de estudantes.

As ilustrações e fotografias apresentadas ao longo do texto dos livros, além do caráter elucidativo e pedagógico, agregam força ao design das páginas. A complexidade do conteúdo envolvido na Engenharia Geotécnica encontra nas ilustrações e fotografias um facilitador indispensável. Estas imagens foram trabalhadas da forma gráfica mais clara e articulada possível, tornando mais atrativo e direto o conteúdo extenso e rígido.

\section{Análise de casos e resultados}

Desenvolver material didático para áreas tradicionais de conhecimento, como a engenharia civil, não é tarefa fácil. A precisão exigida para as ilustrações e animações e a grande quantidade de textos e fórmulas que fazem parte desta área exigem um trabalho demorado e minucioso.

A linguagem utilizada pela engenharia, considerando as ilustrações, os textos e as fórmulas, é bem específica e para que se alcançasse um resultado condizente com este contexto no desenvolvimento dos livros digitais, muitos ciclos iterativos de produção foram necessários. Existem padrões de representação específicos para os solos e as estruturas. Essas questões serão apresentadas a seguir.

Para o primeiro livro digital desenvolvido, e o principal deles, algumas ilustrações começaram com simples esboços feitos pelos engenheiros civis envolvidos nos projetos. Até que se passasse a dominar a linguagem gráfica utilizada pela engenharia, muitas reformulações e correções foram necessárias, até que o resultado fosse aceito pelos engenheiros, o que, no 
ponto de vista da gestão de produção do material, em termos de equipe, significa que esta é uma fase de ciclos iterativos, em que são necessários processos de avaliação e correção. Grande parte das fotografias apresentadas também foram produzidas pela equipe envolvida, no intuito de trazer para a sala de aula situações que muitas vezes o aluno não tem a oportunidade de vivenciar academicamente ${ }^{7}$, como é o caso de etapas de obras de fundações ou patologias de fundações.

Isso evidencia que a multidisciplinariedade envolvida em projetos desse tipo, onde é desejável que a equipe comporte não só os profissionais da área, mas também programadores, educadores e designers gráficos, requer que todos trabalhem juntos, tornando o processo produtivo dinâmico e interativo. Este tipo de configuração da equipe de produção vem sendo adotado e estudado por psicólogos europeus e designers desde os anos 80 , numa orientação conhecida como Design Participativo (SPINUZZI, 2002). Uma abordagem de design parecida surgiu uma década depois nos Estados Unidos: este conjunto de práticas foi batizado de design contextual. Constituía-se em um conjunto de estratégias para promover um design centrado no cliente, e que sugeria o uso de técnicas como observação em campo e análise da tarefa. Em seguida, protótipos baseados nestas modelagens deveriam ser construídos e testados. Segundo Carmel et al. (1993, p. 42), práticas orientadas à participação têm como característica a busca de um consenso entre os membros da equipe, em comparação com técnicas como JAD4, objetivo perseguido pelos conceptores do material apresentado neste artigo.

Essa intersecção entre áreas distintas de conhecimento acabou gerando experiências ricas e gratificantes aos envolvidos no processo, o que amenizou os problemas de produção citados acima.

O livro intitulado Problemas, Acidentes e Patologias de Fundações, apesar de ser desenvolvido para o meio digital, configurou-se linearmente na apresentação das informações, aproximandose do texto tradicional, como definido anteriormente.

O segundo livro desenvolvido denominado Ensaios de Campo foi uma reformulação de um livro já publicado na forma tradicional e que também já possuía uma versão digital. Essa necessidade surgiu para que obtivesse uma identidade visual e de navegação com o primeiro livro, no intuito de gerar uma unidade entre esses materiais. Conforme apresenta a Figura 1, pode-se perceber que a programação visual foi mantida, mudando-se apenas o projeto navegacional do primeiro para o segundo caso. A cor utilizada é distinta para fornecer ao usuário uma identificação mais direta através da mesma. 

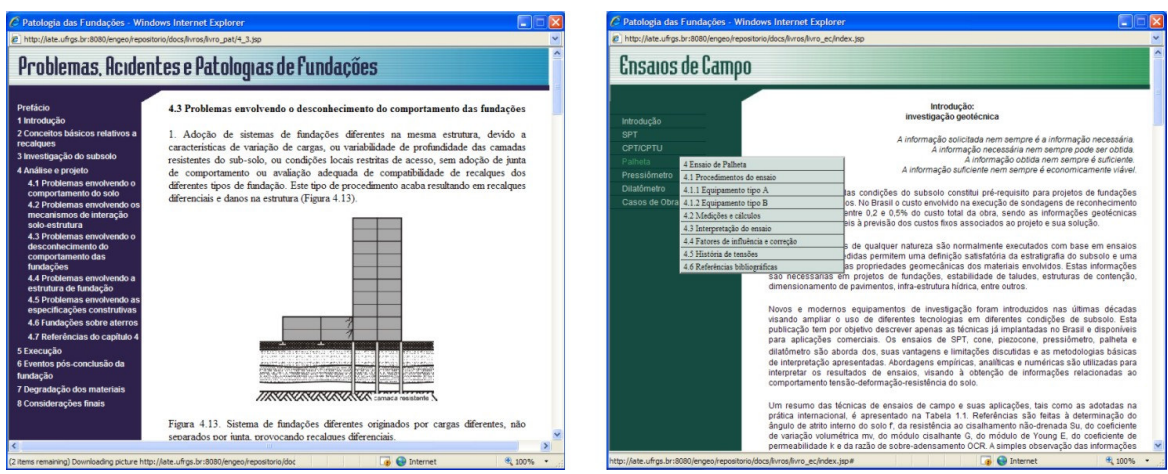

Figura 1 - Os dois primeiros livros digitais desenvolvidos

Enquanto o primeiro apresenta um projeto navegacional linear, através de links textuais para os saltos entre os capítulos, o segundo já apresenta menus para estas ações. No primeiro, é necessário um clique nos itens principais para serem disponibilizados os subitens de cada capítulo. No segundo, basta um clique no menu disponibilizado quando o mouse encontra-se em cima do capítulo relacionado. Embora o acesso à informação seja mais direto no segundo caso, a navegação é melhor orientada no primeiro. No entanto, ambos apresentam o texto de forma linear na área da direita, não permitindo saltos gerados a partir desse texto, mais uma vez mantendo a configuração linear.

A terceiro material produzido é uma apostila de auxilio para algumas disciplinas do curso de graduação da engenharia civil, especificamente da área de Engenharia Geotécnica. Partiu-se se uma seleção de textos, exercícios e materiais fotocopiados que totalizavam mais de 350 páginas impressas. O grande número de equações presentes nestes materiais foi o ponto crítico do trabalho, visto que os softwares de programação Web não apresentam recursos para a apresentação de fórmulas e equações matemáticas.

Além disso, o projeto navegacional desta apostila não permite fácil acesso às informações, conforme mostra a Figura 2. A página principal apresenta os cinco capítulos principais. Um clique em um desses disponibiliza os sub-itens de cada capítulo específico e transfere os demais capítulos para baixo desses sub-itens. Novo clique no sub-item escolhido pelo usuário e então o texto é apresentado na mesma área já definida nos outros livros. Em alguns casos, são necessários muitos cliques para se chegar até a informação desejada, o que compromete a ergonomia do projeto navegacional e às vezes acaba desestimulando o aluno em seu estudo. 

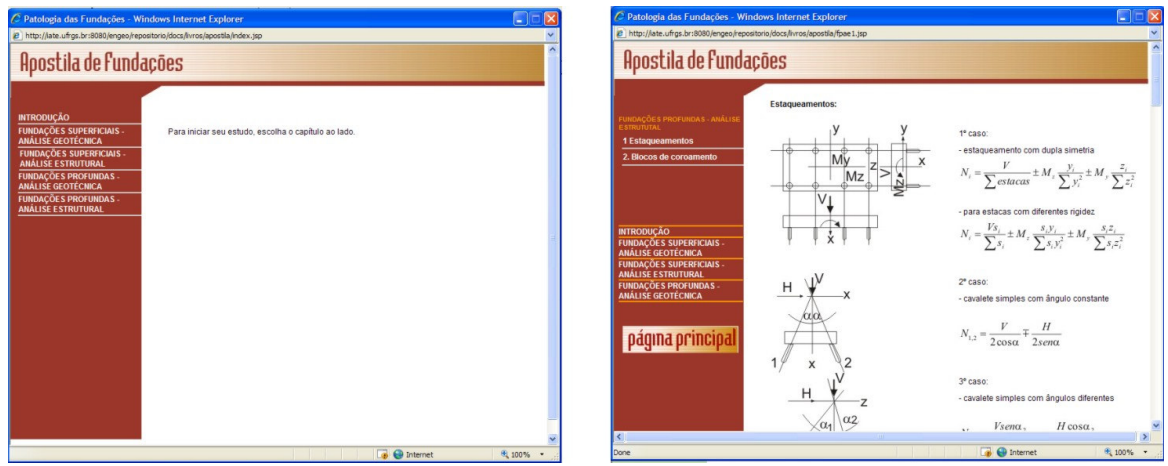

Figura 2 - Apostila digital

A apostila foi desenvolvida baseada no material impresso, porém muitas alterações em relação aos sub-itens de cada capítulo vinham sendo feitas ao longo do percurso. Por este motivo, procurou-se desenvolver uma estrutura de páginas que permitisse autonomia entre os capítulos, ou seja, permitisse que alterações pudessem ser feitas em um capítulo sem que isso acarretasse a necessidade de alterações nos demais. Isso resultou em um material digital de navegação confusa, o que torna explícita a necessidade de se ter o material bem estruturado antes de partir para as outras etapas do desenvolvimento, já que o projeto navegacional só deve ser desenvolvido tendo a real visão de todas as seções e subseções que deverão constar no material (Preece, 2002). Uma sugestão é utilizar jogos de cartão, como por exemplo, CARD (Collaborative Analysis of Requirements and Design), uma técnica participativa que objetiva analisar e redesenhar o fluxo da tarefa através de jogos de cartão. Cada ícone ou componente da tela é representado em um cartão, e, enquanto o usuário descreve uma determinada tarefa, o facilitador mostra o cartão relacionado. Em seguida, o usuário é convidado a expressar suas idéias para melhorar algum aspecto do sistema em estudo através dos cartões. Assim, ele representa um fluxo melhorado da tarefa, mostrando um cartão após o outro, podendo o procedimento filmado e analisado posteriormente (Muller, 2001).

\section{Conclusões}

Nos casos apresentados, apesar dos pontos negativos e de soluções não tão otimizadas, o material desenvolvido fornece aos alunos interessados uma fonte de pesquisa importante para o planejamento das disciplinas e rica em conteúdo. Além de informações inéditas, disponibiliza também materiais já existentes de forma estruturada, clara e didática. Através do esforço dos professores envolvidos, um apanhado de textos, artigos, exercícios e exemplos servem ao aluno através de uma mesma mídia, bastando acessar um ambiente virtual previamente desenvolvido, de forma integrada a um repositório de objetos educacionais em múltiplas mídias, o que corrobora a posição sugerida pelos autores do presente trabalho, sobre a importância do planejamento integrado dos recursos e sua utilização para 8 V. 5 № 1, Julho, 2007 
necessidades específicas do conteúdo e do momento do trabalho docente e do aprendizado do aluno.

Em todos os casos, priorizou-se a linearidade das informações como solução, em detrimento da hipertextualidade, para facilitar a inserção do aluno no conjunto do conteúdo. 0 fato de se identificarem soluções melhores ou piores indica a importância de se desenvolver metodologia de pesquisa que possa apontar vantagens e desvantagens de tipos de soluções, relativas ao design, ao uso de recursos de menus, pop-ups ou outras possibilidades, de acordo com o software de produção, independentemente do fator linearidade.

Ressalta-se que projetos deste tipo possuem inúmeras vantagens. A principal, já citada, é a de disponibilizar conteúdo cumulativo e estruturado, em uma só mídia, consolidando repositórios de objetos educacionais flexíveis, com conteúdos de vários tipos, apresentados em várias formas de representação, para a área da Engenharia Geotécnica. Além disso, trata-se de um material didático de natureza ecológica, visto que uma grande quantidade de páginas de papel transforma-se em alguns megabytes de informações digitais, as quais podem ser acessadas pelo aluno de qualquer computador conectado à rede.

\footnotetext{
${ }^{1}$ Neste momento inicial da Web, os elementos multimídia resumiam-se a imagens, texto e applets Java organizados em hipertextos.

${ }^{2}$ A título de depoimento individual das autoras, ao participar de equipes multidisciplinares de produção, não poucas vezes os próprios professores de áreas como biologia ou engenharia expressaram textualmente sua necessidade de direcionar o aprendizado de forma linear e cumulativa, em vários pontos do programa, além de terem comentado seu desagrado com desenhos animados que competem pela atenção dos alunos, ocupam espaço nas telas e não contêm informação relevante.

${ }^{3}$ Ver Torrano, in: Hesíodo (1992) a descrição da relação do mundo grego com a memória oral, a qual seria um dom das musas, particularmente aos poetas, os aedos, que representavam, à época, o máximo poder da tecnologia de comunicação, ao transmitir as histórias, as vitórias dos governantes, os costumes e as leis, de cidade em cidade: "O poeta, portanto, tem na palavra cantada o poder de ultrapassar e superar todos os bloqueios e distâncias espaciais e temporais, um poder que só lhe é conferido pela Memória (Mnemoxsyne) através das palavras cantadas (Musas). Fecundada por Zeus Pai [...] a Memória gera e dá a luz às Palavras Cantadas, que na língua de Hesíodo se dizem Musas" (p. 17)

${ }^{4}$ Bits e átomos era exatamente o título do primeiro artigo do livro A Vida Digital (Negroponte, 1999), no qual o autor explorava as vantagens do mundo virtual, que não ocupa espaço e ubiquamente se instala à disposição de vários usuários, simultaneamente.

${ }^{5} \mathrm{O}$ aplicativo ENGEO é um sistema Web integrado por um repositório de objetos educacionais (composto de vídeos, imagens, textos e animações), um dicionário (inglês/português) de expressões técnicas de Engenharia Geotécnica e por um conjunto de livros em formato hipertextual (que são objetos deste artigo). Foi desenvolvido durante a dissertação de mestrado de Ferreira Filho (2005) e é utilizado como apoio ao ensino presencial de Engenharia de Fundações, uma sub-área da Engenharia Geotécnica. Acessível pelo endereço http://iate.ufrgs.br:8080/engeo/.

${ }^{6}$ Ressalta-se que não se realizou uma experimentação com os alunos para comprovar a maior eficácia do material educativo produzido linearmente. $O$ projeto foi desenvolvido levando-se em consideração a experiência dos professores da Engenharia envolvidos, que optaram pela linearidade. Este tema poderá ser abordado em projetos de pesquisa futuros. Este artigo apresenta a discussão da linearidade como uma opção possível para áreas como a Engenharia, abrindo caminho para discussões e reflexões sobre ambos os padrões de navegação nas informações.

${ }^{7}$ A visualização in situ de técnicas ou processos, para uma turma de acadêmicos de Engenharia, pode não ser possível, por exemplo, por questões de segurança envolvida no acesso às obras, ou porque uma vez executada uma etapa, a subseqüente impede a visualização da anterior, ou ainda inexistência de uma obra de Engenharia executando uma técnica ou processo que esteja sendo abordada em sala de aula naquele momento.
} 


\section{Referências Bibliográficas}

BERNERS-LEE, T. Information management: a proposal. Hypertext proposal. Internal Report. CERN, 1990. Disponível em: <http://www.w3.org/History/1989/proposal.html>. Acesso em: fevereiro de 2005.

BUSH, V. As We May Think. Disponível em: <http://www.w3.org/History/1945/ vbush/>. Acesso em: fevereiro de 2005.

CARMEL, E.; WHITAKER, R. D.; GEORGE, J. F. PD and Joint Application Design: a Transatlantic Comparison. Communications of the ACM, v. 36 n. 6, 1993. p.40-48

CYBIS, Walter de Abreu. Abordagem Ergonômica para Interfaces Homem-Computador. Polígrafo não publicado. Universidade Federal de Santa Catarina, Laboratório de Utilizabilidade, Florianópolis, 1997.

HESÍODO, Teogonia. A origem dos deuses. Tradução de Torrano, Jaa. São Paulo: lluminuras, 1992. $166 \mathrm{p}$.

FERREIRA FILHO, R. C. M. Contribuições ao uso de novas tecnologias da informação e comunicação no ensino de engenharia, 2005. Universidade Federal do Rio Grande do Sul. Programa de Pós-graduação em Engenharia Civil. Porto Alegre - RS, Brasil, 2005. Dissertação de mestrado.

LÉVY, Pierre. As tecnologias da inteligência: o futuro do pensamento na era da informática. Rio de Janeiro: Ed. 34, 1993. 203 p.

MORE, M; KEARSLEY, G. Distance Education, a System View. Wadsworth Publishing Company, USA, 1996.

MULLER, M. J.: Layered Participatory Analysis: New Developments in the CARD Technique. In: CHI'01 - Conference on Human Factors in Computer Systems. New York: ACM, 2001, p. 90-97.

MUNARI, Bruno. Design e Comunicação Visual: Contribuição para uma metodologia didática. São Paulo: Martins fontes, 1997. 345 p.

NEGROPONTE, Nicholas. A vida digital. 2. ed. São Paulo: Companhia das Letras, 1999. 231 p. NIEDERAUER, Juliano. Livros eletrônicos vão substituir os livros de papel? Disponível em: <http://www.niederauer.com.br/artigos/01112002.php>. Acesso em: junho de 2007.

OLIVEIRA, J. M. P. ; FERNANDES, C. T. . Sistemas Hipermídia Adaptativos Educacionais: Breve Panorama e Modelo de Referência. In: Congresso Nacional de Ambientes Hipermídia para Aprendizagem. Florianópolis, Universidade de Santa Catarina, 2004.

PINHEIRO, Margarida e MENDES, Antônio José. Contribuições para a construção de um curso EAD para adultos. In: V Conferência Internacional de TIC na Educação. Disponível em: 
<http://www.nonio.uminho.pt/challenges/05comunicacoes/Tema2/12 MargaridaPinheiro.pdf>. Acesso em: junho de 2007.

PREECE, Jeny. Interaction design : beyond human-computer interaction. New Yourk: John Wiley \& Sons, 2002. $519 \mathrm{p}$.

SPINUZZI, C.: A Scandinavian Challenge, a US Response: Methodological Assumptions in Scandinavians and US Prototyping Approaches. In: SIG'02. Ontario - Canada, p. 208-215.

TIMM, Maria Isabel; SCHNAID, Fernando e ZARO, Milton Antônio. Contexto histórico e reflexões sobre hipertextos, hipermídia e sua influência na cultura e no ensino do século XXI. In: Ensino de Engenharia: do positivismo à construção das mudanças para o século XXI. Porto Alegre: Editora da UFRGS, 2006. p. $189-218$. 